\title{
Práticas de adoções caninas: um estudo documental comparativo entre instituições latino-americanas ${ }^{1}$
}

\author{
JULIANA GOMES DA CUNHA* \& AGNALDO GARCIA
}

\begin{abstract}
São escassos os estudos que tratam de adoções caninas por humanos, ainda que pareça crescente o interesse de estudiosos pelo relacionamento entre essas espécies. Nesse sentido, nosso objetivo foi ampliar o debate comparando práticas de equipes envolvidas em adoções caninas de três países latino-americanos: Brasil, México e Argentina. Para isso, analisamos documentos de internet por meio do uso de informações extraídas de cinco sites de equipes de cada país. Os dados foram divididos em oito "pontos de análise", sendo então descritos e analisados. Observamos muitas semelhanças entre as práticas dos três países, sugerindo que um movimento de preservação da vida canina é compartilhado, ao menos em parte, na realidade latino-americana. Os princípios e missões mostraram-se voltados à questão dos direitos dos animais e seu bem-estar, carecendo de maiores investigações em relação aos cães. Assinalamos a possibilidade de ampliação do estudo, por meio da inclusão de dados de outros países e regiões.
\end{abstract}

Palavras-chave: Adoção canina; relacionamento entre espécies; bem-estar animal; cães; humanos.

There are few studies about canine adoption by humans, although it seems crescent the interest for the relationship between those species. In this sense, we aimed to broaden the debate with the comparison of the practices of the institutions involved in canine adoptions of three Latin American countries: Brazil, Mexico and Argentina. In order to do so, we gathered online data from the websites of five institutions in each country. The obtained data was divided into eight "analysis points", and then described and analyzed. We observed, in general, a strong consonance between the practices of the three countries, suggesting amotion towards the preservation of canine life that is shared, at least partly, in the Latin American reality. The principles and missions showed themselves engaged in promoting respect to the animal rights and animal welfare, which lacks further investigations in relation to dogs. We'd like to point out the possibility of expanding the study by including data from other countries and regions.

Keywords: Canine adoption; relationship between species, animal welfare, dogs, humans.

\section{Introdução}

O relacionamento entre cães e humanos é reconhecidamente interessante por sua antiguidade e suas peculiaridades em relação ao ocorrido com outras espécies. Apesar disso, trata-se de temática incipiente em estudos científicos recentes, tanto em contexto brasileiro quanto no latino-americano em geral (Cunha \& Garcia, 2013). DeMello (2012) sugere que os cães foram os primeiros animais a serem tratados como animais de estimação e que esse processo teria tido início há cerca de 3000 anos. Nesse sentido, Lorenz (1997) menciona que nenhum outro animal doméstico transformou tão bruscamente seus hábitos e alcançou domesticação tão genuína quanto o cão. É evidente, porém, que suas funções ao longo do tempo se alteraram consideravelmente (Almeida, Labarthe, \& Paiva, 2010; Gómez, Leonardo, Atehortua, Camilo \& Padilla, 2007).

Historicamente, DeMello (2012) relata que antigamente, na Europa, os cães de caça tinham altos preços e que provavelmente também serviam para companhia. Na China, os pequineses e os shih tzu teriam sido originalmente cães de companhia. Além disso, os pequineses eram considerados divinos por se parecerem com os leões sagrados do budismo, e os shih tzu, apesar de pequenos, eram usados como cães de guarda em palácios imperiais. Ainda segundo a autora, acredita-se que na Idade Média muitas

\footnotetext{
1 Trabalho produzido pela aluna de mestrado Juliana Gomes da Cunha sob orientação de Agnaldo Garcia, subsidiado pela Coordenação de Aperfeiçoamento de Pessoal de Nível Superior (CAPES) no Programa de Pós-Graduação em Psicologia da Universidade Federal do Espírito Santo.

* Autora correspondente: juliana88gomes@gmail.com
} 
Práticas de adoções caninas: um estudo documental comparativo entre instituições latino-americanas

freiras e monges tinham animais de estimação, apesar de a Igreja Católica ter classificado essa prática como heresia.

Gómez et al. (2007) relembram o pastoreio, a caça, as participações em espetáculos, guerras e resgates como funções de cães em épocas remotas - ainda que assim seja, em algum grau, ainda hoje - e, atualmente, a companhia. Gutiérrez, Granados \& Piar (2007) e Jakovcevic e Bentosela (2009) concordam, por sua vez, que ser "mascote" é o mais positivo e difundido modo de interação homem-animal da atualidade.

Devido ao sucesso da ligação entre animais e humanos, esses são, por vezes, compelidos a viver na companhia de animais de estimação. O relacionamento, porém, nem sempre é acompanhado de responsabilidade humana, que deveria existir desde o momento em que o animal é adquirido (Seixas, 2012). Quando isso não ocorre, o indivíduo isenta-se do compromisso e da ética que deveria pautar todas as relações sociais. Nesse contexto, Garcia (1999) ressalta que o respeito pelas plantas, pelos animais e pela natureza, de forma geral, são reflexos da atitude humana perante os outros humanos. Além disso, segundo o autor, crimes contra a natureza configuram crimes contra a humanidade. É possível inferir, então, que informações de como pessoas relacionam-se com outras pessoas podem ser extraídas a partir do relacionamento entre elas e seus animais de estimação (Merizio \& Garcia, 2006). Os relacionamentos homem-homem e os homem-animal poderiam até mesmo ser analisados cientificamente de modos semelhantes (Enders-Slegers, 2000).

O panorama recorrente de negligências em relação aos animais domésticos é creditado a questões como a disseminação de doenças, o excesso de reprodução, mordeduras, acidentes e abandonos em locais públicos (Souza, 2011). Cerqueira (2012) menciona razões socioeconômicas e culturais como propiciadoras do aumento da taxa de animais abandonados e, por conseguinte, acolhidos em abrigos. A responsabilidade pelo trato com o animal, outrora não assumida, é então repassada para outrem. Orihel e Fraser (2008) mencionam o sucesso em curto prazo de um programa de reabilitação para diminuir a agressão entre cães. É importante ressaltar os méritos da implantação desse tipo de programa para o aumento das chances de adoção canina bem-sucedida, tendo em vista a eliminação ou diminuição de comportamentos pouco desejáveis pelos humanos, como a mencionada agressividade entre cães. Josa e Suárez (2008)2008 retomam a temática da agressividade canina, dessa vez em relação aos humanos. Consideram urgente avaliar a possibilidade de ocorrência de comportamento agressivo de cães abrigados quando em contato com pessoas desconhecidas, levando em consideração a repercussão e dimensões que esses episódios podem alcançar quando em convivência diária com o humano. Assim, ajustes nesse caso são relevantes quando há o objetivo de criar vínculos adequados entre as duas espécies.

Com o intuito de facilitar processos de adoção, Protopopova, Gilmour, Weiss, Shen e Wynne (2012) treinaram cães para olhar nos olhos do possível adotante quando este está visitando o abrigo. Verificaram, porém, a pouca eficácia desse olhar em contraposição à forma de admissão no abrigo e às características e aptidões de certos tipos de raças caninas. Nesse sentido, cães "de colo" e dóceis seriam mais propensos a serem adotados do que cães voltados para a luta ou esportistas, o que também está diretamente relacionado às suas estadias mais longas nos abrigos. Em suma, é possível inferir que diferentes práticas são administradas com o objetivo de tornar genuína a ligação homem-cão desde os contatos iniciais. Para Lorenz (1997), o tipo de cão escolhido revela muito sobre o indivíduo, e mais revelador ainda é o vínculo estabelecido posteriormente entre dono e animal de estimação.

Broom e Molento (2004) destacam que o bem-estar deve dizer respeito a características do animal individual, e não a algo que lhe foi proporcionado por humanos. Assim, "o bem-estar do animal pode melhorar como resultado de algo que lhe seja fornecido, mas o que se lhe oferece não é, em si, bem-estar" (p. 2). É aberta a possibilidade de pensarmos se o que é fornecido a um animal que passa a viver em companhia de humanos mediante processos de adoção está relacionado diretamente à melhoria do seu bem-estar, já que por vezes os ambientes de abrigos são considerados insalubres e impróprios para a manutenção de vidas animais. Ferreira e Sampaio (2010) comprovaram, por exemplo, que há menor bem-estar em cães tidos como "exclusivos" em um lar do que em cães que viviam em companhia de outros, realidade comum dos abrigos de animais. Além disso, as autoras inferiram que o desenvolvimento das atitudes positivas e o comprometimento com os cuidados do animal, apesar de proporcionar-lhes boa qualidade de vida, não são suficientes para garantir seu bem-estar. Provavelmente isso ocorre porque fatores de natureza subjetiva, inerentes à relação entre as espécies, também têm efeito decisivo nesse sentido. 
Tendo em vista essas reflexões, visamos com este trabalho comparar as práticas de adoção canina - um dos meios de iniciar um relacionamento entre humanos e a outra espécie - por pessoas. Estas, organizadas em equipes e empenhadas nessa questão, localizam-se em três países distintos. Mais especificamente, pretendemos: a) dar relevância às questões de bem-estar animal e a humanos envolvidos nos procedimentos de adoção canina; b) verificar aspectos de criação, financiamento e ideologia de cada uma das equipes; c) compreender os métodos e as formas de trabalho utilizadas pelas equipes para lidar com as adoções, dando maior relevância ao processo de adoção, e d) apontar os pontos fortes e fracos e os possíveis aprimoramentos dos procedimentos utilizados por equipes brasileiras envolvidas em trabalhos de adoção de animais, levando em consideração os métodos empregados nos outros países, que podem facilitar o estabelecimento de vínculos entre humanos e animais.

\section{Métodos}

\section{Material de análise}

Optamos por analisar documentos da internet. Segundo Flick (2009), "uma parte saliente da internet e World Wide Web é sua variedade infinita de páginas da Web. Estas podem ser vistas como uma forma especial de documento ou texto, e analisadas desta forma" (p. 249). Assim, foram analisadas informações extraídas de sites de equipes que promovem a prática de adoção canina em três países latino-americanos. Entre os sites escolhidos, cinco foram de equipes brasileiras, cinco de equipes argentinas e outros cinco de equipes mexicanas, totalizando 15. Optamos, além disso, por referirmo-nos às equipes pelas letras iniciais de seus países, seguidas de um número estabelecido aleatoriamente para cada uma delas.

As equipes são: AdoPet (B1); Associação de Proteção e Bem-Estar Animal (B2); União Protetora dos Animais Carentes (B3); Núcleo de Educação Ambiental Francisco de Assis (B4); ProAnima (B5); Asociación Protectora de Animales de Santiago de Querétaro AC (M6); Sociedad Protectora de Animales de Zihutanejo (M7); Protectora Nacional de Animales A.C. (M8); Asociación de Refugio y Protección de Animales (M9); Gente por la Defensa Animal A.C. (M10); Asociación Protectora San Nicolás de Lomas de Zamora (A1 1); Refugio Canino de Venado Tuerto (A12); Mascotas em adopción (A13); Manos Amigas Ituzaingo (A14) e Adopta Abandonados (A15).

\section{Procedimentos de coleta de dados}

Os sites das equipes em questão foram selecionados mediante pesquisa na ferramenta de busca Google. Como requisitos para inclusão no estudo, nos restringimos a páginas de grupos ativos até então e que contemplassem quantidades expressivas de informações propostas nos pontos de análise apresentados no item "Resultados e discussão". . Tendo em vista que o interesse maior do trabalho foram as questões relativas à adoção propriamente dita, nos pautamos na seleção de sites que trouxessem tais informações.

\section{Procedimentos de organização e análise dos dados}

As informações coletadas foram agrupadas e analisadas de acordo com o país de origem em cada um dos Pontos de Análise, considerando as temáticas. Os dados foram então analisados de forma comparativa entre as práticas dos países e cruzados com as informações obtidas da literatura pertinente. Tendo em vista o caráter descritivo do trabalho, optamos por realizar a apresentação dos resultados juntamente com a discussão.

\section{Resultados e discussão}

\section{Aspectos de criação, financiamento e ideologia das equipes}

Histórico das equipes

Das cinco equipes brasileiras analisadas, três (B2, B3 e B5) denominam-se, em suas descrições, como associações, enquanto B1 denomina-se "comunidade de auxílio na adoção de pequenos animais", tendo sido criada por alunos de uma Faculdade de Medicina Veterinária de uma universidade federal, aonde prestam serviços gratuitamente à comunidade. Já B4 denomina-se "Núcleo de Educação Ambiental".

Quanto às equipes mexicanas, em consonância com as informações encontradas em sites brasileiros, três delas (M6, M9 e M10) intitulam-se associações. A equipe M7 possui o título de "Sociedade Protetora de Animais" e, por fim, a equipe M8 
Práticas de adoções caninas: um estudo documental comparativo entre instituições latino-americanas

é definida como uma organização civil sem fins lucrativos.

As equipes argentinas apresentam as seguintes intitulações: "Associação" (A11 e A15); "refúgio", nomeação dada à A12, que destaca que pertence a uma associação protetora de animais sem fins lucrativos; e "grupo de pessoas" (A14). Este ressalta em seu site que não é uma entidade protetora nem um abrigo. A equipe A13 refere-se a si mesma todo o tempo pelo seu nome próprio, sem tomar posse de nenhuma titulação complementar.

Foi notado, portanto, predomínio da denominação "associação" entre as equipes dos três países, sendo três destas brasileiras, três argentinas e uma mexicana. Cerqueira (2012) define associações de abrigo como "organizações não-governamentais da sociedade civil com finalidade pública e sem fins lucrativos" (p. 5). Além disso, cada organização é caracterizada por sua filosofia norteadora, algo que difere entre elas de maneira ampla e de diversas maneiras, desde a forma de lidar com os animais e programas de controle populacional até os serviços que envolvem a sociedade.

Segundo Cerqueira (2012), dentre os tipos de associações de abrigo enquadram-se as instituições de controle animal, as organizações humanitárias e as instituições de abrigo. Vale ressaltar, porém, que pode haver formas distintas de definir e nomear cada tipo de equipe em suas modalidades, não havendo enquadramentos oficialmente estabelecidos para tal, sendo este apenas um modelo. Assim, cabe a cada equipe suas próprias descrições e denominações.

As datas de fundação das equipes diferiram consideravelmente entre as mexicanas, as brasileiras e argentinas. Quatro dos cinco sites de equipes brasileiras trazem entre suas informações a época de sua criação. Duas delas (B1 e B3) foram fundadas em 2006 e as outras duas (B4 e B5) em 2003. As equipes mexicanas têm suas datas de criação do ano 1982 (M7) a 2005 (M10). As demais equipes datam suas fundações em 2001 (M6), 1992 (M8) e 1995 (M9). Os sites das equipes argentinas, por sua vez, deixaram lacunas em relação às épocas de suas criações. Apenas a equipe Al1 determina que sua fundação foi há aproximadamente 15 anos, e a A15 data a criação de seu centro de zoonoses em 2006.

Foi possível inferir que três das equipes mexicanas e uma argentina foram fundadas a mais tempo do que as brasileiras em geral. Talvez, as primeiras tenham sido fundadas quando as questões urgentes nas fundações de abrigos e outras ações para o resgate de animais das ruas e seus cuidados ainda não eram tão abrangentes quanto na época da fundação das demais, já no século XXI. Porém, não foram encontradas bibliografias que comprovassem ou que remetessem a essas hipóteses. Sabe-se, entretanto, que o papel exercido pelo cão na sociedade alterou-se ao longo do tempo, tendo outrora sido empregado fortemente em atividades de caça, pastoreio, guerras e espetáculos (Gómez et al., 2007). Atualmente tem seu papel de mascote bem difundido (Jakovcevic \& Bentosela, 2009), o que parece ter vindo acompanhado por superpopulação e abandono.

O fato é que o abandono de animais é recorrente. Seixas (2012) e Souza (2011) apontam a não responsabilização do ser humano pelo trato e suporte dos animais, o que acaba gerando reproduções desenfreadas e abandonos em vias públicas, com consequente demanda de abrigamento. Segundo a Organização Mundial de Saúde (OMS), há apenas no Brasil mais de 20 milhões de cães abandonados (Anda, 2014).

\section{Arrecadações de fundos e colaborações}

Os gastos das equipes B2, B3 e B5 são cobertos por meio de doações. B1 e B4 não apresentam em seus sites informações sobre doações ou apoio da comunidade em geral. Portanto, vale ressaltar que em ambas não há manutenção de abrigos. Duas das equipes mexicanas (M8 e M9) não apontam explicitamente em seus sites as formas como os subsídios para sua manutenção são arrecadados. M6, porém, ressalta o apoio recebido de voluntários. Além disso, relata em seu texto que a partir de 2008 passou a receber auxílio da empresa Pedigree, através de um programa de apoio à adoção animal. Quanto à M7, é relatado que sobrevive de vendas de produtos, além do recebimento de ofertas de doadores, assim como a equipe M10.

A arrecadação de fundos das equipes argentinas também se dá de maneiras variadas. A equipe A11 destaca que "toda atenção veterinária, medicamentos, alimentação e transferências são resolvidas particularmente pelos membros da associação sem nenhum subsídio". A A12 conta com um grupo de voluntários e com a arrecadação de doações. Solicitam, portanto, que as pessoas doem dinheiro, alimentos ou materiais como toalhas, panos, coleiras, recipientes plásticos ou metálicos, água oxigenada e álcool. A13 adiciona à arrecadação de doações o fato de lidar com um esquema de apadrinhamento de cães ou gatos em particular e com a venda de livros doados em bom estado. A equipe A14 apenas 
identifica-se como uma rede de pessoas em contato contínuo, onde cada um se ocupa com o cuidado de alguns cães. Não é explicitado no conteúdo do site de A15 o recebimento do apoio de pessoas ou entidades externas aos próprios integrantes, além da evidenciada parceria com o governo municipal para cuidados como castração.

É comum entre os três países que a maioria das equipes conta com doações, o que evidencia a grande necessidade de envolvimento de pessoas, seja da sociedade civil, seja de instituições privadas ou governamentais. Há também equipes que revelam dividir os cuidados dos animais entre si, exigindo quantidade e variedade considerável de voluntários com habilidades para lidar com a higiene, alimentação, tratamentos e resgates. Apenas uma equipe argentina ressaltou o apoio do governo municipal em ações como castração. Não é possível afirmar, porém, que as demais equipes não estão vinculadas com esse tipo de serviço ou se apenas não os ressaltaram nos conteúdos de seus sites. A equipe M6 relata participação no programa de adoção de uma grande empresa do ramo de animais de estimação. Aqui cabe ainda a definição proposta por Cerqueira (2012), segundo a qual as "organizações humanitárias" teriam como base de manutenção donativos de entidades privadas, da população ou mediante campanhas para arrecadação de fundos, estando em consonância com o relatado pela maioria das equipes, salvo suas peculiaridades.

É possível que a união entre abrigos e programas ou campanhas de empresas - levando em consideração a pertinência dos modelos e práticas seguidos - seja uma das soluções cabíveis, desde que os subsídios que podem ser gerados e a amplitude de divulgação das iniciativas sejam ponderados. São necessários, porém, mais dados e relatos provenientes de produções científicas, por ora escassas.

Princípios ou missão das equipes

As missões ou princípios empregados pelas equipes brasileiras apresentam grau expressivo de semelhanças entre si, salvo as peculiaridades. Os princípios são: "Encaminhar os pequenos animais abandonados para novos lares adotivos" (B1); "Educar para promover a proteção e o bem-estar animal e a preservação ambiental" (B2); "Estimular o amor e respeito à vida, controle de natalidade de animais, a adoção de animais carentes, o equilíbrio ambiental e combater o abandono de animais na capital do Ceará, Fortaleza" (B3); "A busca do bem-estar animal, através de Educação Ambiental, trabalho de fomentação de adoções de cães e gatos (guarda responsável) e atendimento veterinário aos animais de pessoas carentes ou de pessoas que abrigam muitos animais resgatados de rua" (B4) e "Promover a harmonia nas interações entre humanos e animais" (B5).

As equipes mexicanas também apresentam com clareza suas missões ou princípios, com exceção da M6, que não a explicita em seu conteúdo. A equipe M7 tem por princípio fundamental, que inspira e guia todas as suas atividades, evitar o sofrimento desnecessário dos animais. A missão da M8 é

reorientar a população para que ajude a resgatar, reabilitar física e emocionalmente e abrigar em casas bondosas todos os animais do país, para atingir uma relação harmoniosa de cada indivíduo com todas as formas de vida com quem partilhamos o planeta (Protectora Nacional de Animales A. C., s.d).

A equipe M9 revela que trabalha para criar soluções que beneficiem tanto os animais como o homem. Por último, M10 apresenta três objetivos principais a fim de alcançar sua missão: fazer valer as leis de proteção animal em estados mexicanos por meio de litígio e do trabalho legislativo; fomentar o respeito aos animais através da educação e da divulgação de seus direitos, visando prevenir maus tratos, e combater a superpopulação animal, como uma das formas de prevenir problemas de saúde e de segurança da população humana.

As missões das equipes argentinas são: "Conscientizar o ser humano de que os animais, cujo reino eles também pertencem, são parte de um ecossistema que nós compartilhamos e que, portanto, não é uma entidade isolada do planeta" (A11). Seguindo a mesma linha filosófica de A11, a de pertencimento do mundo também aos animais, a equipe A12 ressalta que sua meta é dar aos animais o lugar que merecem dentro da sociedade. A13 é mais sucinta no trecho do site que diz respeito à sua missão: "Mascotas en adopción se formou com a finalidade de resgatar, reabilitar e logo dar em adoção aqueles cães e gatos abandonados ou maltratados na região de Del Viso, Partido de Pilar". A14 tem por "objetivo final que os municípios legislem e cumpram leis ou ordenanças que solucionem o problema dos animais abandonados". A15 trabalha para alcançar objetivos como: empregar nos conteúdos escolares temas acerca do cuidado dos animais de estimação e fazer 
Práticas de adoções caninas: um estudo documental comparativo entre instituições latino-americanas

valer a legislação, com cumprimento de itens como castrações gratuitas e a Declaração de Município não eutanásico.

Algumas medidas têm sido empregadas como alternativas à prática da eutanásia para controle populacional de cães, como educação populacional e controle da natalidade como preconizado pela OMS (Orlandi, 2011). García-Rodríguez et al. (2008) apresentam a experiência de um centro de acolhimento de animais em Barcelona, Espanha. Lá, os sacrifícios animais foram suspensos por mandato desde o ano de 2003, sendo acompanhado de aumento inicial na taxa de abandonos, estabilizada posteriormente. Além disso, inicialmente ocorreram dúvidas em relação ao sacrifício de animais acometidos por enfermidades contagiosas, como a cinomose, o que ocasionou endemia posteriormente controlada. Pondera-se, então, no contexto social e de nacionalidade em que está inserido, que a aplicação de eutanásia em casos de determinadas doenças infecciosas ou por questões relacionadas à agressividade, e mediante prescrição facultativa, deve ser estudado a fim de evitar a morte de muitos animais jovens e saudáveis envolvidos nesse contexto.

Em geral, as equipes das três nacionalidades apresentam missões de apoio às vidas e aos direitos dos animais, tais como reabilitação, não abandono ou negligência, equilíbrio ambiental, inserção dos animais em lares onde sejam tratados com carinho e amor e a busca pelo seu bem-estar. Parece legítimo o empenho por essa busca, já que segundo Broom e Molento (2004) o que influencia mais no bem-estar da maioria dos animais são as condições a que estão sujeitos durante o maior período de suas vidas. Se as instalações em que vivem são inadequadas, isso gerará um bem-estar empobrecido. Essa situação é mais grave do que um episódio doloroso de curta duração, apesar destes geralmente causarem maior impacto e mobilização da população. Hubrecht (2008) acredita que ainda há muitas questões a serem estudadas acerca do bem-estar de cães em abrigos. Dentre estas, indaga qual é a quantidade de cães que podem ficar alojados juntos e se o contato com humanos é realmente mais valioso do que o contato com outros cães. Assim, para fundamentar e tornar práticos os princípios e missões que as equipes carregam, foi notório o aparecimento de verbos como educar, reorientar e conscientizar voltados à população, visando realizar possíveis modificações no modo de lidar com os animais e com a natureza em geral. Uma sugestão relevante estava presente no site da equipe A15, que sugeria empregar nos conteúdos escolares temas relativos à relação afetiva e legal entre humanos e animais.

Assim, a educação da população para o contato adequado com animais de estimação, ainda que não tratada como conteúdo escolar, é salientada por autores como Paploski et al. (2012) e Loss, Mussi, DeMello, Leão e Franque (2012). Estes ressaltam o baixo grau de conhecimento dos donos de animais em relação aos aspectos preventivos e de cuidados de saúde, tais como vacinação, vermifugação e recolhimento de fezes em vias públicas, ou seja, questões que afetam não apenas os que mantêm contato próximo com o animal, mas toda a sociedade. Salientando o baixo conhecimento da população, Carvalho et al. (2011) ressaltam a importância do trabalho permanente de conscientização sobre posse responsável de animais e a importância do controle de zoonoses. Assim, a execução de campanhas, grupos de conversa, palestras e debates figuram como auxiliares do relacionamento humano-cão.

\section{Aspectos do processo de adoção e outros trabalhos realizados pelas equipes}

Trabalhos realizados pelas equipes e espécies de animais envolvidas

A equipe B 1 meramente realiza o trabalho de encaminhar os animais abandonados para lares adotivos. B2 realiza, além disso, palestras e eventos educativos nos campos de proteção animal, da preservação ambiental, da saúde e do bem-estar humano e animal, estando em conformidade com B5. Esta soma à sua realidade comissões e outras instâncias pertinentes à proteção animal, à preservação ambiental e à formação de alianças entre diversos setores da sociedade civil juntamente com o poder público para o avanço dos direitos dos animais. A equipe B3, assim como a B4, realiza esterilizações a baixo custo e tratamentos veterinários. Além disso, dedica-se ao resgate de animais e à adoção propriamente dita. A quarta equipe aponta, além do já mencionado, a realização de procedimentos cirúrgicos.

A equipe M6 realiza, além de adoções de animais, trabalhos de resgate e esterilizações. M7 efetua ampla gama de atividades, dentre as quais: dar refúgio aos animais abandonados, perdidos, enfermos, atropelados ou abusados; proporcionar tratamento, reabilitar e liberar espécies silvestres; possui um programa permanente de adoção de animais 
domésticos; manejo de campanha permanente de esterilizações a baixo custo para donos de cães e gatos que possuem recursos escassos; colaboração com autoridades em campanhas de vacinação; controle de fauna nociva e combate ao comércio ilegal de fauna silvestre em risco de extinção, e estabelecimento de um prêmio anual de mérito em prol dos direitos dos animais na região, sendo um para os cidadãos e outro para funcionários.

São estabelecidas pela equipe M8, além da esterilização e da adoção, comum às equipes supracitadas, orientações para a população sobre os cuidados e necessidades dos animais; resgates; reabilitação física e emocional; tutela e supervisão do bem-estar dos animais em suas novas casas. As atividades realizadas pela M9 são semelhantes com as citadas em relação à M8, com o acréscimo da informação de que não recorrem à eutanásia. As iniciativas da M10 englobam animais domésticos, silvestres e de consumo, envolvendo combate aos maus-tratos de animais, ao tráfico ilegal e à clandestinidade.

Dentre as equipes argentinas, a equipe A11, além de realizar procedimentos relacionados à recuperação e posterior adoção caninas, realiza atividades como a esterilização de machos e fêmeas "para evitar nascimentos descontrolados de cachorros que logo podem ser abandonados" e promoção do sentido de solidariedade para os demais necessitados, sejam eles animais ou pessoas. A12 cuida de animais vítimas de abandono, dando-lhes abrigo, alimentação e reabilitando sua saúde para que sejam adotados. A13, por sua vez, realiza diversas etapas anteriores ao processo de adoção, como resgates e recuperação de animais. Depois de resgatado, é feito um exame veterinário para conhecer em que estado o animal se encontra, sendo vacinado e desparasitado. Além disso, é marcada uma data para sua castração. A equipe A14 realiza unicamente o trabalho ligado à adoção, tendo em seu site somente informações pertinentes a esse tipo de procedimento. Finalmente, a equipe A15 realiza, além de adoções, esterilizações gratuitas e massivas dos animais.

Os dados supracitados evidenciam semelhanças entre os trabalhos realizados pelas equipes dos três países. Em essência, as iniciativas giram em torno de resgates, reabilitação e posterior disponibilização para adoção; refúgio e cuidados veterinários, além de esterilização. Esta aparece, como mencionado anteriormente, como importante alternativa à prática da eutanásia. A execução da eutanásia teria sido, segundo Orlandi (2011), recomendada em 1973 pelo $6^{\circ}$ Informe Técnico da OMS (Orlandi, 2011), sendo ainda bastante utilizada mundialmente, apesar de já ter sido superada e de ter tido sua ineficácia e prejuízos comprovados (Souza, 2011). A própria OMS, em seu $8^{\circ}$ Informe Técnico de 1992 (Orlandi, 2011), opta por recomendar a substituição do método pelo controle da natalidade animal e pela educação da população (Garcia, Galderòn \& Ferreira, 2012; Seixas, 2012; Souza, 2011). Sendo assim, a adequação das práticas das equipes a essa realidade mostra-se urgente e ética, reservando ao animal o direito à vida, como ressalta Chalfun (2009).

A equipe B5 relata a formação de alianças com setores diversos da sociedade civil e do poder público para pôr em prática os direitos dos animais, que nem sempre são reconhecidos, como considera Gutiérrez et al. (2007). Ele também salienta o aparecimento de movimentos de defesa diante do questionamento do papel dominante do humano em relação as outras espécies. Para Souza (2011), há uma falha em reconhecer o status moral dos cães, desconsiderando que são "animais sencientes, portadores de interesses, capazes de experimentar dor e sofrer fisica e mentalmente" (p. 116).

Quanto às espécies de animais submetidas às intervenções, B1 relata lidar com animais de estimação, sem especificar as espécies. As demais equipes brasileiras, em contrapartida, deixam explícito em seus conteúdos o fato de lidarem com cães e gatos. As equipes M6 e M8 lidam com cães e gatos. M9 lida apenas com cães, e as equipes M7 e M10 incluem em suas ações animais silvestres, e nesta está incluída ainda a realização de trabalhos com os chamados animais de consumo. As equipes A1 1, A12, A14 e A15 lidam com os cuidados relativos apenas aos cães. A13 inclui a espécie felina em suas ações.

Cinco das equipes em análise, sendo quatro argentinas, lidam apenas com cães. Além disso, todas as demais lidam com a espécie canina somada a outras. Isso corrobora com dados de trabalhos anteriores (Barrera, Jakovcevic \& Bentosela, 2008; Paploski et al., 2012; Protopopova et al., 2012) sobre o elevado número de cães abandonados por todo o mundo e, consequentemente, apoiados por ações de controle de superpopulações, dentre as quais estão as realizadas pelas equipes em questão. Apesar da mencionada superioridade numérica da população canina, os gatos também têm tido sua população aumentada, sendo que apenas no Brasil parece haver cerca de 10 milhões de gatos abandonados, segundo a OMS (Anda, 2014). Nesse contexto, o trato de cães e gatos foi relatado por sete das 15 equipes. 
Práticas de adoções caninas: um estudo documental comparativo entre instituições latino-americanas

Existência de abrigos

As equipes B1, B2 e B5 não possuem abrigos. B5 justifica o fato da seguinte maneira:

\begin{abstract}
abrigos se tornam chamarizes para o abandono e desresponsabilizam governo e sociedade para as causas da superpopulação e abandono desses animais. A ProAnima acredita que o movimento de proteção animal precisa ir além da dinâmica desesperada de recolhimento de animais - emergência após emergência - e estruturar ações estratégicas de longo alcance. Precisamos transformar a ideia de que protetor animal é aquele que "cata" todos os bichos que encontra pela frente e que vive de desespero em desespero (ProAnima, s.d.).
\end{abstract}

A mesma ideologia é seguida por B2, que conta com colaboradores para disponibilizar lares temporários aos animais. B3 mantém dois espaços para abrigos de cães e gatos retirados das ruas, ainda que sem sede própria. Por fim, apenas B4 relata em seu site a existência de sede própria.

Todas as equipes mexicanas, por sua vez, realizam atividades em instalações de abrigo, ainda que não explicitem em seus sites se são imóveis próprios, alugados ou cedidos definitiva ou temporariamente. Dentre as equipes argentinas, as equipes A11 e A12 apresentam abrigos próprios. Esta possui a seguinte descrição em seu site: "é provido de instalações adequadas para atenção veterinária e canis especiais para as cadelas com crias ou animais que chegam enfermos". Já A13, A14 e A15 não possuem abrigos. A última ressalta em seu site que julga que "o abrigo não ataca a origem do problema, e sim suas consequências. Em síntese, o que deve ser feito é controlar o crescimento populacional dos animais com métodos éticos e quem deve levá-lo a cabo é o Estado".

Das 15 equipes em estudo, nove apresentam instalações onde os animais sob seus cuidados são abrigados para tratamentos, reabilitação e refúgio propriamente dito. Em contrapartida, seis não possuem abrigos - ainda que realizem diversos cuidados aos animais -, sendo três brasileiras e três argentinas. Parece haver consenso entre os argumentos que embasam esse fato, apesar de nem todas as equipes o justificarem. Assim, B2, B5 e A15 acreditam que o abrigamento mostra-se como uma atitude desesperada de retirada de cães da rua, o que acaba por isentar de responsabilidade a sociedade e o governo; segundo A15, é primeiramente o governo que deve tomar atitudes que ataquem a origem do problema.
Sobre isso surge, novamente, discussões pertinentes à adoção de políticas de controle de natalidade e práticas de educação e esclarecimento populacionais relacionados a uma série de questões que envolvem humanos e cães, isoladamente ou em interação, como apontado por Garcia et al. (2012), Seixas (2012) e Souza (2011).

Pessoas que compõem as equipes

As pessoas que se dedicam aos trabalhos com os animais, no caso, as equipes, apresentam perfis semelhantes, apesar de terem peculiaridades. Assim, no Brasil, B1 é composta por alunos de uma universidade federal, sem que o conteúdo do site forneça mais informações. B2 é composta por professores, médicos veterinários, biólogos, advogados, economistas, jornalistas, entre outros. Todos são associados ou colaboradores. B3 convoca voluntários e destaca que "cada um contribui na mesma medida de suas possibilidades, mas cada compromisso assumido deve ser cumprido. Uns têm mais tempo livre, outros só dispõem de algumas poucas horas por semana". Assim, está em consonância com B5, que traz como complemento: "Não somos um grupo de cobranças e amargura; temos uma atitude positiva. Mas isso não nos isenta de sermos sérios no que fazemos. É o que esperamos de novos voluntários”. B4 não indica quem são as pessoas que a compõe.

Dentre as equipes mexicanas, M6 é composta por voluntários, além de uma recepcionista e um profissional de limpeza, ambos remunerados. M7 é dirigida por uma mesa diretiva integrada por um presidente, um tesoureiro e um secretário. Além disso, aproximadamente 70 pessoas entre membros ativos, colaboradores e uma pessoa remunerada encarregada da recepção, alimentação, limpeza e cuidado dos animais também a compõem. M8 é composta por voluntários, e em sua solicitação por estes destaca que o trabalho na organização é uma ótima oportunidade para estudantes de medicina veterinária. M9 também agrega voluntários, e os definem como "profissionais independentes com um só objetivo: ajudar os animais e promover o respeito, amor e compaixão por eles na cidadania". Do mesmo modo, M10 é formada por pessoas que "dedicam seu tempo, recursos econômicos, materiais e habilidades em prol da aplicação dos preceitos do humanismo na proteção e defesa dos animais".

Dentre as equipes argentinas, a equipe A11 agrega entre seus profissionais docentes, donas de casa, comerciantes e estudantes, movidos pelo objetivo 
de ajudar os animais. A12, A14 e A15 são compostas por voluntários. A13 não informa diretamente quem a compõe, mas trabalha com um sistema de apadrinhamento. Assim, a população pode colaborar, caso deseje, com os gastos e cuidados do animal.

As informações sugerem que grande parte dos que se dedicam aos trabalhos com animais são voluntários, sem que haja discrepâncias sobre isso entre os países. M8 destaca que para estudantes, como no caso dos componentes da B1, trata-se de uma oportunidade de aprendizado. As motivações que impulsionam os demais voluntários a se dedicarem a esses trabalhos, por vezes árduos e dispendiosos, parecem ter aspectos altruístas, de apoio à vida $\mathrm{e}$ amor aos animais, como abordado anteriormente no ponto que trata dos princípios e missão das equipes. Ferrari, Loftus \& Pesek (1999) verificaram que pessoas jovens se dedicam mais a trabalhos voluntários que envolvam abrigos animais, enquanto pessoas de mais idade demonstram preferência com o trato de outros humanos. Segundo os autores, os jovens reportam obtenção de experiências de carreiras ao realizarem esses trabalhos, concordando com o mencionado por M8. Reportam, além disso, alívio de emoções adversas, sendo essa uma forte motivação para o voluntariado.

A equipe M7, em particular, estabelece um prêmio anual de mérito por atitudes em prol dos animais, sendo oferecido aos cidadãos em geral e aos funcionários, demonstrando valorização de indivíduos que se inserem nesse tipo de atividade. Salvo contextos e meios sociais de cada grupo, a possibilidade de valorização dos que intermedeiam procedimentos de adoção pode ser uma atitude que demonstra cuidado e interesse pelo seu bem-estar, aspecto também pouco considerado pela literatura científica.

Souza (2011) enfoca o trabalhador - possivelmente remunerado - de instituições que lidam com o sacrifício de animais. Destacam que quando o trabalho traz envolvimento prolongado com alta carga emocional, pode-se produzir estado de esgotamento, conhecida como Síndrome de Burnout. O quadro envolve, entre outros sintomas: cansaço crônico, diminuição da autoestima, perda da satisfação com o trabalho e problemas para dormir. Assim, como forma de diminuir as repercussões da situação, por vezes são utilizados pelos trabalhadores mecanismos como o afastamento emocional do animal ou dessensibilizacão. Podem ser assumidas, nesse sentido, atitudes de indiferença para com o animal, como rudeza, frieza, crueldade ou negação do seu valor e até mesmo de sua existência. DeMello (2012) também menciona o desenvolvimento de um quadro de estresse crônico, atingindo funcionários que por vezes veem nesse tipo de trabalho a possibilidade de ajudar e salvar vidas animais, enquanto que para outros trata-se de trabalho como outro qualquer.

Procedimentos relativos à adoção

Os procedimentos que envolvem o processo de adoção também apresentam pontos de divergência e semelhança em contexto brasileiro. A equipe B1 trabalha com os seguintes passos: preenchimento de formulário existente no site; caso a pessoa tenha escolhido um animal do catálogo presente no site, deverá anotar o nome do animal no campo "detalhes" do formulário; se a pessoa não encontrar o animal preferido nas listas disponíveis, deverá também descrever seu desejo no campo "detalhes" do formulário; quando o animal ideal for identificado, o interessado é avisado; feito isso, o possível adotante receberá um e-mail informando o local onde poderá conhecer o animal que melhor se encaixou com o perfil requerido; dúvidas deverão ser remetidas à página de contato do site.

A equipe B2 organiza-se de forma para que os associados e colaboradores que têm condições mantenham em lares temporários gatos e cães durante seu tratamento e recuperação, para em seguida serem encaminhados para adoção. Assim, a equipe tem como pilar central a campanha de adoção, ocasião em que os animais já se encontram castrados, desverminados, com antipulgas e em boas condições de saúde. Segundo a equipe, "é nesta ocasião, quando as famílias buscam por um mascote, que encontramos a oportunidade de educar, informar e formar cidadãos conscientes de suas responsabilidades e deveres". As datas e horários das campanhas são divulgados no site e ocorrem em diversos pontos da cidade de Curitiba. B3 segue as seguintes regras para adoção: ter uma coleira em mãos e transporte para levar o animal, e reservar espaço para o animal dormir, brincar e passear.

Seguindo também o modelo de "ponte" entre possíveis adotantes e os animais, B4 lida com animais de estimação que não são mais desejados por seus donos, e que por isso desejam doá-los. Assim, a equipe possui um cadastro de pessoas que têm interesse em doar e as que têm interesse em adotar, bem como de quem deseja certo tipo de animal de estimação. Além disso, há animais para doação no núcleo da equipe. $\mathrm{O}$ interessado em adotar pode visitar 
Práticas de adoções caninas: um estudo documental comparativo entre instituições latino-americanas

o núcleo, ligar para informar-se sobre os animais disponíveis ou ter acesso ao cadastro no site. Mediante contato com a equipe, o possível adotante passará por uma pequena entrevista e preencherá um termo de adoção gratuita. Os animais encaminhados para adoção pela equipe já são esterilizados e vermifugados. Os que não estão nessa situação terão que ser adotados mediante compromisso firmado com o adotante de levá-lo para o procedimento de esterilização assim que for possível. Todos os animais adotados passam a ter atendimento clínico veterinário na instituição durante um ano, incluindo vacinação e outros procedimentos médicos necessários.

B5 assume o posicionamento de que é necessário haver uma escolha mútua para que o processo de adoção se concretize. A etapa inicial ocorre por meio de preenchimento do questionário ou por telefone. A equipe realiza conversa com o interessado sobre as características do animal, suas demandas de saúde e temperamento. A intenção, segundo a equipe, é auxiliar na reflexão sobre as responsabilidades envolvidas na adoção de um animal. Com base nessa conversa, é agendada uma visita aos animais que se encontram em lares temporários diferentes, o que pode justificar o deslocamento para mais de uma casa. Assim, se ocorrer uma boa interação inicial entre o animal e o adotante, é agendada visita à casa do interessado na presença do animal, já munido de carteirinha de vacinação, histórico e plaqueta de identificação. A casa deverá estar com a organização necessária para o acolhimento do animal. Ocorre então nova conversa e orientação, e tendo sido confirmada a adoção, o adotante assina um termo de compromisso com o bem-estar do animal. Caberá à equipe o acompanhamento e adaptação.

A equipe M6 apresenta como requisitos para adoção: ter sido aprovado na entrevista pré-adoção, apresentar comprovante de domicílio, pagar cota de recuperação de $\$ 400$ pesos mexicanos e entregar o formulário de compromisso de adoção. As solicitações de adoção podem também ser feitas por telefone. Todos os animais são entregues esterilizados, desparasitados, vacinados e com placa de identificação. Além disso, não são entregues animais para menores de idade, para maiores que vivam com os pais, mas que não possuam consentimento destes para a adoção, ou para pessoas casadas cujo cônjuge não consentiu a adoção.

A equipe M7 não especifica procedimentos específicos para adoção. Já M8 traz detalhadamente os procedimentos a serem seguidos para a adoção de um animal. Em primeiro lugar, o interessado deve refletir se pode ser um dono responsável, levando em consideração que o animal não pode ser abandonado e deve ser tratado adequadamente. Depois, deve selecionar o companheiro ideal, considerando, entre outros aspectos, se devem ser adultos ou não, suas características físicas, seu sexo, quem vive na mesma casa e se todos estão de acordo com a adoção. O terceiro passo consiste em uma entrevista. $\mathrm{O}$ adotante, nesse ponto, deve realizar uma doação no valor de $\$ 400$ pesos mexicanos. Por fim, o animal é entregue na casa do adotante. A equipe ressalta que, feita a adoção, serão realizadas supervisões periódicas via telefone ou pessoalmente.

A equipe M9 apenas informa que conta com quase cem cães em um abrigo e que estes buscam uma casa e o carinho de uma família. Por fim, M10 relata que seus cães e gatos são adotados por lares mexicanos, mas também por estrangeiros. Quando a adoção se consolida em outro país, os voluntários recebem o animal e entregam-no ao novo lar, prestando acompanhamento para ter a certeza de que estão seguros em suas novas famílias.

A equipe A1 1 auxilia o Centro de Zoonoses de sua região, levando os animais para serem cuidados em seu abrigo. Assim, os animais depois de recuperados são disponibilizados para adoção responsável. Mediante consolidação da adoção, a equipe acompanha o período de adaptação e a qualidade de vida do animal em seu novo lar. A12 ressalta a possibilidade das famílias interessadas em adotar um animal visitá-los no abrigo. A equipe não detalha, porém, os procedimentos que devem ser executados para concretizar a adoção. Já A13 apresenta pormenorizadamente os passos a serem seguidos para a adoção de um animal. Assim, em um primeiro momento, é observado o temperamento, o comportamento e a interação do animal com outros animais e humanos. É feito, então, um diagnóstico para determinar, entre outras coisas, qual seria sua função no novo lar e o ambiente ideal para ele. Logo após são publicadas fotos em diferentes meios de comunicação, como redes sociais, sites dedicados ao oferecimento de mascotes para adoção e anúncios em jornais. São direcionadas entrevistas aos adotantes em potencial. Os requisitos para adoção são: ser maior de idade, morar na Argentina, ir pessoalmente buscar o animal, ter o acordo de toda a família, apresentar documento de identidade e fornecer um número de telefone ou outro serviço. Ocorrida a adoção, o animal é entregue com uma chapa identificadora com números de contato do grupo e um número que corresponde ao animal. Além disso, os 
dados do animal são atualizados em um sistema que permite o acompanhamento da adaptação e vida do animal no novo lar. A14 orienta os interessados em adotar um animal a eleger alguns cães na galeria de fotos. Em seguida, deve escrever um e-mail ou enviar o Formulário de Adoção preenchido. A equipe ressalta que, para adotar, o interessado deve considerar aspectos como a idade e o tamanho do animal, sua residência e seus recursos financeiros disponíveis para lidar com os custos do animal. A última equipe não possui nenhum tipo de descrição relacionada ao processo de adoção.

Verificou-se que grande parte das equipes das três nacionalidades entregam os animais vermifugados e esterilizados ou sob compromisso de submissão do animal ao procedimento posteriormente. É inegável a importância dessa ação para a manutenção da população canina em equilíbrio, como discutido anteriormente.

A equipe B5 fala de uma identificação mútua entre adotante e adotado. Sendo assim, em uma das etapas do processo de adoção, o animal é levado para a casa do adotante em potencial acompanhado de membros da equipe para a verificação do grau de envolvimento no contato inicial. Outra medida facilitadora do processo de adaptação e adequação do animal ao novo lar é realizada por A13, através de estudo - anterior à divulgação da adoção - do perfil do animal e do papel que provavelmente virá a desempenhar na família, além do tipo mais adequado de moradia.

Esse pensamento é compartilhado por Jakovcevic e Bentosela (2009), que consideram relevante o conhecimento de traços individuais do comportamento do cão e de seu temperamento a fim de direcionar cães para funções como as de policial, guia, companhia ou resgate, e para detectar questões ligadas à conduta, além de facilitar relações mais equilibradas entre cães e humanos. Marston e Bennett (2003) destacam a necessidade de estudar aspectos físicos e fisiológicos dos adotantes em potencial, a criação prévia de animais de estimação, os níveis de renda, as circunstâncias de residência, a composição familiar e o perfil psicológico e suas expectativas, em processo similar ao realizado para adoção de crianças.

A equipe B4 oferece aos adotantes um ano de acompanhamento veterinário, incluindo vacinação. Diante disso, o adotante precisa estar ciente e de acordo com a proibição de abandonar o animal. Um dos fatores desencadeadores do abandono de animais, segundo Vučinić et al. (2009), é a falta de condições financeiras para o trato do animal. Logo, essa ação parece relevante, pois é necessário ponderar os custos envolvidos e a viabilidade do voluntariado, tendo em vista a necessidade de profissionais como os médicos veterinários.

Segundo Vučinić et al. (2009), outro acontecimento que favorece o abandono de animais é a entrada de novo membro na família ou a não concordância de cônjuges ou moradores da casa com a criação do animal. Assim, M6 e A13 não entregam o animal sem o consentimento do cônjuge ou dos outros moradores da casa, como os pais.

O fato da adoção ocorrer gratuitamente é apontado como facilitador de negligências no trato dos animais. Porém, não foi possível encontrar dados bibliográficos relacionados à questão. Nesse sentido, M6 e M8 destacam que não realizam adoções gratuitamente, ainda que não justifiquem o fato. Ambas cobram taxas de $\$ 400$ pesos mexicanos, nomeada por M6 como "cota de recuperação".

Argumentos apresentados pelas equipes em defesa da adoção canina

As equipes trazem nos textos de seus sites, em geral, argumentos persuasivos favoráveis ao processo de adoção, ainda que de formas diferenciadas. Assim, a equipe B1 julga a adoção como "um ato de amor" e diz que "o animalzinho adotado será seu amigo fiel para todo o sempre". B2 complementa que

a satisfação de ver um animal em estado de debilitação totalmente recuperado sendo encaminhado para um lar amoroso é indescritível e torna-se motivação para prosseguir nas ações, acreditando sempre que há seres humanos capazes de tantas atrocidades, há tantos outros capazes de imensa nobreza e compaixão (Probem, s.d.).

A equipe B3, por sua vez, alega que ter um animal influi na saúde física e mental de humanos, tornando-os menos suscetíveis a males como asma e alergias. Em adição, afirmam que ter um animal auxilia crianças a assumirem noções de companheirismo e responsabilidade.

Esta afirmação é endossada por B4, que julga a criação de um animal de estimação importante na formação de crianças. Além disso, acrescentam ao rol de benefícios à saúde a diminuição da incidência de depressão, auxílio na recuperação de doentes com menor tempo de internação, diminuição do 
Práticas de adoções caninas: um estudo documental comparativo entre instituições latino-americanas

uso de medicamentos, melhor controle do estresse, pressão arterial e redução de riscos de problemas cardiovasculares. B5, entretanto, não se foca muito nos argumentos que visam a persuadir a população. Baseiam fortemente seu trabalho no foco, ou seja, buscam atingir as raízes dos problemas que levam ao abandono e aos maus-tratos de animais. Em relação às equipes mexicanas, apenas M10 apresenta argumentos em defesa da adoção. Indicam assim que quando um animal é adotado duas vidas estão sendo salvas, pois ao adotar um, deixa-se espaço para outro animal no abrigo.

As equipes A11 e A12 apresentam argumentos favoráveis à ajuda aos animais, não ficando limitadas ao processo de adoção. Segundo A11

no exato momento em que somos agentes de uma obra de caridade com seres de capacidades distintas das nossas, sentiremos realmente em nosso interior a presença de Deus que nos sorri. Não esqueçamos que é a atitude de uma pessoa em relação à sua comunidade que determina a forma como responderão (Busco Mascotas, s.d.).

A equipe A13 argumenta que ao adotar uma mascote estará salvando duas vidas, a do animal adotado e a do que ocupa seu lugar. Para A14, o indivíduo deve questionar-se se compraria um amigo. Caso a resposta seja negativa, deve refletir sobre o porquê de comprar um cão, já que é considerado como o melhor amigo do homem. Segundo eles, a amizade não se compra, e não há ninguém mais agradecido e carinhoso do que um cão abandonado. Sugerem ainda que consultem um médico veterinário acerca da resistência dos cães de raça mista, sendo constatado que estes resistem consideravelmente mais do que cães de raça pura. A15 não utiliza argumentos em defesa da adoção, embora implemente trabalhos nesse sentido no Centro de Zoonoses com o qual colabora.

Os argumentos em defesa da adoção envolvem questões como amizade entre humanos e cães, benefícios à saúde humana e formação de crianças. Essas informações são endossadas por González e Landero (2011), que relacionam a interação de humanos com cães a índices maiores de saúde mental e índices menores de estresse. Handlin, Nilsson, Ejdeback, Hydbring-Sandberg e Uvnas-Moberg (2012) mencionam alterações nos níveis de oxitocina e cortisol em humanos e cães em interação. Já Merizio e Garcia (2006) verificaram em estudo brasileiro que pais classificam a relação entre seus filhos e cães como amizade. Consideram os animais boas companhias, carinhosas e que demonstram gostar das crianças, além de estabelecerem laços afetivos fortes e por vezes protegerem a casa.

Somados a isso encontram-se argumentos referentes ao envolvimento social na questão do apoio aos animais e na manutenção de abrigos. Nesse sentido, três equipes (B3, M10 e A13) afirmam que quando um animal é adotado dois animais são ajudados e até mesmo salvos: o que foi adotado e outro que poderá ocupar a vaga do anterior no abrigo ou lar temporário. O apelo mostra-se pertinente, pois segundo Barrera et al. (2008), em grande parte da América Latina os abrigos são lotados e impróprios para a quantidade de cães desabrigados. Além disso, acabam por tornarem-se moradia permanente para a maioria dos animais, tendo em vista o pouco interesse populacional em efetuar adoções e o baixo índice dos que de fato adotam.

\section{Considerações finais}

Foram observadas fortes consonâncias entre as práticas relativas à adoção dos três países em questão, sugerindo um movimento de preservação da vida canina compartilhado, ao menos em parte, na realidade latino-americana. Ainda assim, segundo Barrera et al. (2008), a situação dos abrigos desses países parece beirar o caos, com instituições superlotadas e cães que passam a viver abrigados até que morram. Notou-se também a grande preocupação com o controle populacional da espécie canina e com a realização e garantia de esterilização dos que adotam o cão ainda filhote por grande parte das equipes. Os princípios e missões mostraram-se voltados à preservação do equilíbrio entre as espécies e aos direitos e bem-estar animal, estes caracterizados pelo objetivo geral de "diminuir o sofrimento físico, comportamental e psicológico de animais sob nossa guarda" (Molento, 2007, p. 226). Apesar da legitimidade das ações voltadas ao bem-estar dos animais e da crença de que este pode ser alcançado com maior facilidade em ambientes familiares tradicionais, Ferreira e Sampaio (2010) afirmam que o tratamento cuidadoso ofertado aos animais nesses casos, apesar de proporcionar-lhes boa qualidade de vida, nem sempre está associado ao bem-estar, já que pesam sobre ele fatores de natureza subjetiva. Mostra-se válido, ainda, ponderar em que medida o contato com seres humanos é importante em oposição a limitar ou privar seu contato com seres da mesma espécie (Hubrecht, 2008). 
A realização desse estudo comparativo acabou por restringir-se quase totalmente a descrição das equipes, dada a homogeneidade das informações. Ao longo das discussões a possibilidade de divisão por países foi diminuída. Foram realizados, assim, apontamentos de peculiaridades expressivas das equipes, dando relevância às práticas por vezes pouco consideradas, mas tidas como pertinentes. Assim, enquadram-se medidas como as de B5, de estudar a identificação inicial entre possíveis adotantes e adotados no ambiente que seria sua moradia caso a adoção fosse concluída: o lar do adotante. A13, por sua vez, considera cabível a realização de estudo do perfil do animal antes de disponibilizá-lo para adoção. A repercussão positiva desta ação deve ser estudada em contexto das equipes brasileiras, tendo em vista sua complexidade relativamente baixa. Outras medidas, ainda que expressivas, requerem mudanças políticas de maior complexidade, como a sugerida por A15, onde a educação em relação aos animais deveria ser incluída em conteúdos escolares.

Foi notado, além disso, a escassez de estudos em relação aos processos de adoção em âmbito latino-americano em geral. Assinalamos a possibilidade de ampliação do estudo por meio da inclusão de dados de outros países e regiões. Vale ressaltar ainda a possibilidade de problemas relacionados ao método escolhido, que foi a utilização de dados extraídos de sites, os quais estão propensos a livre atualização do material com alterações das informações coletadas (Flick, 2009). Apesar disso, não desconsideramos a importância desses dados, pois os materiais veiculados de outros locais e países na internet são de fácil acesso.

\section{Referências}

Almeida, F., Labarthe, N. V., \& Paiva, J. P. (2010). Divulgação dos princípios da guarda responsável: uma vertente possível no trabalho de pesquisa a campo. Revista Eletrônica Novo Enfoque, 9(9), 64-86.

Agência de Notícias de Direitos Animais (2014). Cresce para 30 milhões o número de animais abandonados no Brasil. Recuperado em 07 de Julho de 2015 de http:/ /www.anda.jor.br/01/03/2014/cresce-30milhoes-numero-animais-abandonados-brasil

Barrera, G., Jakovcevic, A., \& Bentosela, M. (2008). Calidad de vida en perros alojados en refugios: intervenciones para mejorar su bienestar. Suma Psicológica, 15(2), 337-354.

Broom, D. M., \& Molento, C. F. M. (2004). Bem-estar animal: conceito e questões relacionadas - revisão. Archives of Veterinary Science, 9(2), 1-11.

Busco Mascotas. (s.d.) Información y noticias. Recuperado em 7 de julho de 2015 de http://www.buscomascotas. com.ar/sociedadprotec.htm.

Carvalho, A. A. B., Grisólio, A. P. R., Bueno, G. M., Testi, A. J. P., Martins, M. C., Portela, L. C., Servidone, J. S., \& Nunes, J. O. R. (2011). Caracterização da população de cães e gatos e avaliação do nível de conhecimento dos moradores sobre zoonoses e posse responsável dos animais de estimação, em bairros do município de Jaboticabal/SP. Revista Ciência em Extensão, 7(2), 158-159.

Cerqueira, C. R. E. (2012). Contributo para a promoção da saúde e do bem-estar animal em instituições de abrigo (Dissertação de Mestrado). Faculdade de Medicina Veterinária, Universidade Técnica de Lisboa, Lisboa.

Chalfun, M. (2009). Animais humanos e não-humanos: princípios para solução de conflitos. Revista Brasileira de Direito Animal, 5, 125-144.

Cunha, J. G., \& Garcia, A. (2013). Relacionamento homem-cão: uma revisão. In A. Garcia, F. N. Pereira, \& M. S. P. Oliveira (Orgs.), Relações interpessoais e sociedade (pp.117-132).Vitória, ES: GM.

DeMello, M. (2012). Animals and society: an introduction to human-animal studies. New York, NY: Columbia University Press.

Enders-Slegers, M. (2000). The meaning of companion animals: qualitative analysis of the life histories of elderly cat and dog owners. In A. L. Podberscek, E. S. Paul, \& J. A. Serpell (Eds.), Companion animal \& us: exploring the relationships between people and pets (pp. 257-271). New York, NY: Cambridge University Press.

Ferrari, J. R., Loftus, M. M., \& Pesek, J. (1999). Young and older caregivers at homeless animal and human shelters: selfish and selfless motives in helping others. Journal of social distress and the homeless, 8(1), 37-49 
Práticas de adoções caninas: um estudo documental comparativo entre instituições latino-americanas

Ferreira, S. A., \& Sampaio, I. B. M. (2010). Relação homem-animal e bem-estar do cão domiciliado. Archives of Veterinary Science, 15(1), 22-35.

Flick, U. (2009). Introdução à pesquisa qualitativa (3a ed.). Porto Alegre, RS: Artmed.

Garcia, A. (1999). Crianças que são cruéis com animais. Pediatria moderna, 35(7), 552-558.

Garcia, R. C. M., Calderòn, N., \& Ferreira, F. (2012). Consolidação de diretrizes internacionais de manejo de populações caninas em áreas urbanas e proposta de indicadores para seu gerenciamento. Ver Panam Salud Publica, 32(2), 140-143.

García-Rodríguez, A., Peracho, V., Villalbí, J. R., Bouis, S., Duràn, J., \& Guix, J. (2008). Avances en la gestión de un centro de acogida de animales de compañía. Gaceta Sanitaria, 22(1), 76-78.

Gómez, G., Leonardo, F., Atehortua, H., Camilo, G., \& Padilla, S. C. O. (2007). La influencia de las mascotas en la vida humana. Revista Colombiana de Ciencias Pecuarias, 20(3), 377-386.

González, M. T. R., \& Landero, H. R. (2011). Diferencias en Estrés percibido, salud mental y física de acuerdo al tipo de relación humano-perro. Revista Colombiana de Psicología, 20(1), 75.

Gutiérrez, G., Granados, D. R., \& Piar, N. (2007). Interacciones humano-animal: características e implicaciones para el bienestar de los humanos. Revista Colombiana de Psicología, 16(1), 163-184.

Handlin, L., Nilsson, A., Ejdeback, M., HydbringSandberg, E., \& Uvnas-Moberg, K. (2012). Associations between the psychological characteristics of the human dog relationship and oxytocin and cortisol levels. Anthrozoos: A Multidisciplinary Journal Of The Interactions Of People \& Animals, 25(2), 215-228.

Hubrecht, R. (2008). The welfare of dogs in human care. In J. Serpell (Ed.), The domestic dog: its evolution, behaviour and interactions with people (pp. 179-198). New York, NY: Cambridge University Press.

Jakovcevic, A., \& Bentosela, M. (2009). Diferencias individuales en los perros domésticos (Canis familiaris): revisión de las evaluaciones conductuales. Interdisciplinaria, 26(1), 49-76.

Josa, J. M., \& Suárez, P. (2008). Valoración inicial del comportamiento de perros en un centro de recogida. Clínica veterinaria de pequeños animales, 28(3), 173177.

Lorenz, K. (1997). E o homem encontrou o cão. Lisboa, Portugal: Relogio D’Água.

Loss, L. D., Mussi, J. M. S., DeMello, I. N. K., Leão, M. S., \& Franque, M. P. (2012). Posse responsável e conduta de proprietários de cães no município de Alegre-ES. Acta Veterinaria Brasilica, 6(2), 105-111.

Marston, L. C., \& Bennett, P. C. (2003). Reforging the bond-towards successful canine adoption. Appl. Anim. Behav. Sci., 83(3), 227-245.

Merizio, L. Q., \& Garcia, A. (2006). O relacionamento entre a criança e o animal de estimação e a amizade com outras crianças: uma análise comparada. In A. Garcia (Org.), Relacionamento Interpessoal - estudos brasileiros. Vitória, ES: GM.

Molento, C. F. M. (2007). Bem-estar animal: qual é a novidade? Acta Scientiae Veterinarie, 35(2), 224-226.

Orihel, J. S., \& Fraser, D. (2008). A note on the effectiveness of behavioural rehabilitation for reducing inter-dog aggression in shelter dogs. Applied Animal Behaviour Science, 112(3), 400-405.

Orlandi, V. T. (2011). Da eliminação de animais em centros de controle de zoonoses. Revista Brasileira de Direito Animal, 6(8), 135-160.

Paploski, I. A. D., Babboni, S. D., González, G. K., Giarola, R. M., Rodrigues, S. A., Cerqueira, A. T. A. R., ... , Victória, J. R. M. (2012). Características dos adotantes de cães na área urbana de Botucatu. Veterinária e Zootecnia, 19(4), 584-592.

ProAnima. (s.d.). O que fazemos. Recuperado em 05 de julho de 2015 de http://www.proanima.org.br//oque-fazemos.html.

Probem. (s.d.). Projetos Probem. Recuperado em 05 de julho de 2015 dehttp://www.probem.org/projetos. php. 
Protectora Nacional de Animales A.C. (s.d.). Quiene somos. Recuperado em 05 de julho de 2015 de http:// www.pnamexico.com/nosotros/quienes-somos.

Protopopova, A., Gilmour, A. J., Weiss, R. H., Shen, J. Y., \& Wynne, C. D. L. (2012). The effects of social training and other factors on adoption success of shelter dogs. Applied Animal Behaviour Science, 142(1-2), 61-68.

Seixas, A. T. F. (2012). Gestão de cães e gatos errantes na área da grande Lisboa (Dissertação de Mestrado).
Faculdade de Medicina Veterinária, Universidade Técnica de Lisboa, Lisboa.

Souza, M. F. A. (2011). Controle de populações caninas: considerações técnicas e éticas. Revista Brasileira de Direito Animal, (8), 115-130.

Vučinić, M., Đorđević, M., Teodorović, R., Janković, L., Radenković-damnjanović, B., \& Radisavljević, K. (2009). Reasons for relinquishment of owned dogs in a municipal shelter in Belgrade. Acta Veterinaria, 59(2-3), 309. 